\title{
A study on the Analysis of the Effects of Government Health Expenditure on Maternal Mortality in 25 Sub-Saharan Africa Countries
}

\author{
Tendani Moseki-Lowani \\ KDI School of Public Policy and Management, 263 Nam-Sejong-ro, Sejong-si 30149, South Korea \\ * lowanitendani@kdis.ac.kr
}

\begin{abstract}
The study conducted examines the effect of government health expenditure on maternal mortality on health care and maternal mortality in 25 Sub-Saharan Africa Countries over the period of 1997 to 2015 and the empirical approach uses longitudinal data. To diminish the possible confounding influence of public health expenditures in the maternal mortality regressions, the study uses panel data run using STATA econometric software. The study finds that in Sub Saharan Africa, public health expenditure has a strong impact on reducing maternal mortality rates. Moreover, the study finds that improvements in access to improved sanitation facilities and external resources all work together to reduce the plausibility of maternal deaths. These findings support previous related empirical evidence for developing countries. Overall, from a policy standpoint, the empirical estimates call for public health policy makers in less-industrialized regions to pay close attention to three very basic measures. These include: improved access to sanitation facilities, efforts to combat HIV and AIDS along with increased public spending on health as these are all important factors that can help to decrease maternal fatalities in Sub Saharan Africa Countries
\end{abstract}

Keywords: Public Health Expenditure; Maternal Mortality; Sub Saharan Africa

DOI: $10.7176 /$ PPAR/9-9-09

Publication date:September $30^{\text {th }} 2019$

\section{Introduction}

Lozano, Wang, Foreman, Rajaratnam, Naghavi, \& Marcus, (2011) state that Sub Saharan Africa (SSA) Countries have to reduce maternal mortality by $75 \%$ as well as achieving their millennium Development Goals target related to the reduction of maternal deaths in 2015. However, despite this achievement, SSA countries still encounter challenges in the provision of maternal health care and curbing maternal deaths. A number of countries in SSA experience political instabilities and conflicts that threaten the general growth, societal solidity and peace. Some are comparatively free from instabilities, but are still having difficulties with regard to improving health related issues (World Health Organization., 2012). The author further indicates that global maternal deaths prevalence was roughly $99 \%$ in 2015 . More deaths which are estimated to be $66 \%$ were prevalent on SSA countries, Southern Asia accounting for approximately 30\%. Areas that are developing have reached about $99 \%$ (302 000) of the global maternal deaths in 2015, SSA having 66\% (201 000), and Southern Asia (66 000). Globally, the calculated value of maternal deaths have reduced across regions and Eastern Asia is the leading region that has managed to curb maternal deaths most by roughly 72\% from 1990 t0 2015(Lozano, et al., 2011).

Meanwhile, SSA and Oceania were one of the least regions that failed to reduce maternal deaths with a great magnitude, Nigeria was one of the countries in SSA that had over one third of all maternal deaths globally, which as estimated to be at (19\%) (World Health Organization, 2015). Statistics on maternal deaths report by World Health Organization (2015) states Central African Republic (881), Chad (856), South Sudan (789), Somalia (732) as the 5 leading countries with high maternal deaths. With the presented studies and statistics, it is found that most deaths happen as a result of HIV and AIDS-related and indirect causes (World Health Organization., 2012). Countries such as South Africa, Swaziland, Botswana, Lesotho and Mozambique had the highest prevalence of deaths occurring as a result of HIV and AIDS indirect related causes, (World Health Organization, 2015).

Even though SSA countries' determinations to advance merit and quality in maternal health care amenities, nations still faces variation of hurdles to advance and progress in maternal health. Therefore, working towards Sustainable Development Goal (SDG) 3 and ultimately preventing maternal deaths requires considering, implementing the suggested initiative and continuing the efforts set MDG 5 as well as making maternal health 
care a priority. Anyanwu \& Erhijakpor, (2007) state that a government which prioritizes maternal health is likely to enhance country's economic growth and high labor productivity thus it is crucial that SSA countries invest on health amenities as well as maternal health care.

\subsection{Statement of Problem}

Maternal mortality is a great health challenge encountered by developing nations, particularly the nations of sub-Saharan Africa. According to World Bank (2000), the maternal mortality ratio is beyond 900 per 100,000 live births in certain countries of sub-Saharan Africa (SSA), comprising of Central African Republic Eritrea, and Guinea Bissau. High maternal mortality affects the overall health outcomes of a nation and its progress. It has been projected that every year at least 1.5 million women die as a result of complications associated with pregnancy and delivery, and 99\% of these deaths take place in emerging countries, accounting for approximately $85 \%$ of the world's births (Royston, 1989). Wagstaff and Cleason (2004), state that the degree, to which government health care expenditure stimulates health consequences, rests on the effectiveness of policies and institutions. Relating government health expenditure to maternal mortality, Grossman states that excellent health considerably impacts a country's growth through effective outcomes from sustainable and efficient health structures (Grossman, 1972). Similarly, Anyanwu and Erhijakpor (2007) states that sufficient and competent health related spending is considered as a significant and fundamental factor in the upgradation and elevation of health status of a country. In contrast, in SSA and other developing countries where income and resources are limited, health spending receives fewer attentions in government financial plans (World Health Organisation, 2010).

"Meanwhile, government expenditure on health facilities in SSA is low and ranges between 3\% and 10\%of the total public health expenditure (World Health Organisation, 2010). Poullier, Hernandez, Kawabata, \& Savedoff, (2002) projected that the proportions of revenue that nations invest on health amenities is more for high return countries, with health expenditure as a share of gross domestic product (GDP) extending from an estimate of $1.5 \%$ to $13 \%$. The largest prevalence are in Europe and the US, Africa. Few areas in Asia have the lowermost in comparison to their input of $19 \%$ to the globe's population. (Poullier et al, 2002)". The authors Poullier et al. (2002) found that OECD region invest an estimated $85 \%$ of the world's total health expenditure towards improving health challenges such as maternal mortality. On the contrary, Africa contributes to only 3\% of the global's health expenditure as against their 10\% share in the global's population (Poullier et al., 2002). The evidences presented above indicates that a strong connection between health care expenditure and health consequences such as maternal mortality is yet to be established, especially at the macro level in SSA (Novignon \& Olakojo, 2012). Although, "Anyanwu and Erhijakpor (2007)" found substantial positive influence of healthcare investment on health consequences, Burnside and Dollar (1998) could not establish any link among the two.

This study is motivated by the different conclusions drawn from discussions on the association between health expenditure and health consequences such as maternal mortality with a precise consideration of 25 SSA countries. Thus, the aim of the study is to gain more in-depth knowledge on the effects of government expenditure on maternal mortality and to suggest policy measures for maternal health care and delivery.

\section{Literature Review}

World Health Organization (2004), defines "maternal mortality is the death of women during pregnancy, childbirth, or in the 42 days after delivery and it still a major encounter to health structures international (p. 89)". Maternal death may be due to both direct and indirect obstetric reasons. SSA faces several challenges with regard to maternal health and this includes pregnancy and birth complications, childhood complications and HIV and AIDS (Kinney, et al., 2010).WHO, (2006) report state that a high number of maternal deaths in Africa occur as a result of direct obstetric problems that happen before the period of child birth. In most cases hemorrhage, hypertension, sepsis, and obstructed labor combined account for $64 \%$ of all maternal deaths (Khan, Wojdyla, Say, Gülmezoglu, \& Look, 2006) while indirect causes such as HIV and AIDS and pneumonia, account for $23 \%$ of maternal mortality..

\subsection{Maternal Health Services Access}

Wirth, Balk, Delamonica, Storeygard, \& Sacks, (2006) found that there are disparities in health care access for individuals in both urban and rural areas and this affects maternal health. For instance, mortality prevalence is low in well developed areas than in rural areas, and remote societies experience more insufficient access to health care. However, some areas that are rapidly developing or developed are linked with congested living 
environments, poor cleanliness, and extensive poverty thus contributing to struggles to access quality health care and ultimately general and maternal mortality.

Similarly, WHO, (2014) emphasised that access to trained and adequate health care lean towards wealth and geography. The reports states that from different surveys that were conducted from 2000 to 2011, results shows great differences in being attended by a well-trained health worker during birth for women from welldeveloped/wealth and poor areas. The widest differences ranging from $70 \%$ difference between the poorest and richest groups were in Guinea, Madagascar and Nigeria, and the smallest difference constituting, approximately $20 \%$, was in Sao Tome (WHO, 2014).

Furthermore, there was a research done in DRC and it was found that prevalence of maternal deaths is high in the areas that conflicts are present especially Eastern provinces of Congo. According to (Coghlan, Brennan, Ngoy, Dofara, Otto, \& Clements, 2006) there were 1,174 maternal deaths per 100,000 live births in the Eastern Provinces of Congo as to 811 maternal deaths in the west. It can be concluded that factors such as political instabilities, conflicts and natural tragedies results in challenges in providing maternal health services as well as sustaining a well-designed health system. Due to these circumstances, people are inhibited to accessing effective health care as a result to lack of equipment, poor referral structures, deteriorating settings of health amenities, loss personnel in the health sector, worsening transportation systems, corruption, authoritarian leaders, poor institutions, and inadequate freedoms (Coghlan, Brennan, Ngoy, Dofara, Otto, \& Clements, 2006).

Other factors associated with poor antenatal care are lack of education, coupled with living in rural areas and lack of financial resources (WHO, 2014). Chad, Ethiopia, Niger and Nigeria have the extensive gaps of health care coverage between the illiterate population and the highest educated, amounting to a coverage of estimated $31 \%$ among the illiterate and $88 \%$ among the highest educated. Meanwhile, on the contrary (WHO, 2014) found that there was slight difference in health care coverage between the developed and poor areas, for instance, in Rwanda coverage was $97 \%$ and $99 \%$ in the poorest and richest areas, respectively.

\subsection{Effects of Government Health Expenditure on Maternal Mortality}

According to (Servan-Mori, Avila-Burgos, Nigenda, \& Lozano, 2016) distribution of public capital on health care is mostly based on population factors. Generally, public expenditure on health strive to improve health conditions through two methods. First, the aim is to improve the accessibility of health amenities through better-quality and availability of prolific efforts such as health investment, health personnel and technology (Servan-Mori, Avila-Burgos, Nigenda, \& Lozano, 2016). Secondly, it aims to reduce economical limitation of individuals and influence their choices and access patterns of health. As a consequence, greater expenditure and investment in any health care system, i.e maternal health leads to improved health outcomes.

A report by (Anyanwu \& Erhijakpor, 2007), states that African health structures encounters enormous financing insufficiencies. Commission for Africa, (2005) highlights that paralleled to international mean of 5.4\% of GDP, SSA public expenditures with a mean of $2.5 \%$ of GDP and is extremely little and short off to afford and deliver primary basic health. Nonetheless, in developed countries, spending on health surpassed US\$2,000 per person per year, while in Africa its generally between US\$ 13 and US\$ 21 in 2001 in 2005 (Anyanwu \& Erhijakpor, 2007). On the other hand, (Commission on Macroeconomics and Health, 2001) suggested that expenditure for health in SSA be increased to US\$ 34 per person per year by 2007, and to US\$ 38 by 2015 , amounting to approximately $12 \%$ of GNP. This is the lowest sum required to distribute primary strategies to address HIV and AIDS, and TB, and maternal infections while other authors suggest a greater topping up of public health and other alternative expenditure that could improve general and maternal health care (Sachs, 2004)

In comparison, other researchers suggest that PHE does not contribute much on health results. To justify this, (Devarajan, Swaroop, \& Zou, 1996; Pritchett, 1996) emphasis that positive health results may be a reflection of the efficiency of disbursements of funds, and it relies on the quality of services delivered by the public and government. Furthermore, "Gupta, Verhoeven, and Tiongson (2002) used cross-sectional data from 1993 to 1994 to study 50 countries of which 11 were SSA and also found that there is a weak relation between increased public expenditure on health and reduction of child and maternal mortality rates. Garret (2007) who examined the challenges of global health contends that in spite of the efforts that aim to respond to the HIV and AIDS pandemic, much of the health funds is invested yet the results are so poor. First, because of strict levels of bureaucracy, and poor health delivery system, health funds accumulated end up not being used effectively thus increasing challenges in health care access. Secondly, corruption plays a role because in many cases there are payments made to untraceable employees, misuse of drugs and illegal selling of drugs (Garret, 2007). In addition, Yaqub, Ojapinwa, and Yussuff (2012) who conducted a study in Nigeria from 1980 to 2008, share the same views that increased public spending on health will not results in nay positive results when other factors like 
corruption are not dealt with.

\section{Methodology}

To demonstrate the effects of Government health expenditure on maternal mortality, a panel data regression is run using STATA econometric software, for the period of 1997 to 2015 . This study primarily uses data from the World Health Organization and countries that limited data in two or more three or more variables was not included in the study. This study uses panel data or longitudinal data because it contains time series observations of a number of countries. The advantage of using panel data setting is the use of either random effect and fixed effect model that creates chance to control the estimation biased resulted from time invariant omitted confounding factors. Hence, in this paper, the researcher uses the panel fixed effect and random effect and apply the Hausman specification test to choose the efficient method. The major challenges in empirical modeling is establishing causal relationship among the key and outcome variable. This is due to the problem of endogeneity that might be due to measurement error, reverse causality and omitted variable bias.

In developing countries where data management is poor the data for maternal mortality and government health expenditure might be recorder with error; thus this might create measurement errors which in turn creates endogeneity, Aigner (1984) supports this as he states that measurement errors can lead to attenuation bias. Hence, attention should be focused on estimating the causal relationship. The problem of reverse causality is unlikely in this study but the problem of unobserved confounding factors can still result biased and inconsistent OLS results. If the unobserved confounding factors are time invariant, the Panel fixed effect estimation will result unbiased and consistent result.

Thus, the researcher uses fixed effects model. "This is because Fixed Effects model is more precise model and mostly has greater significance of freedom and more liability to vary than cross-sectional data which may be viewed as a panel with $\mathrm{T}=1$, or time series data which is a panel with $\mathrm{N}=1$, hence improving the efficiency of econometric estimates, (Hsiao et al., 1995)". The freedom of having many observations for a given variable gives an opportunity of flexibly to generate various changes in the estimators (Griliches \& Hausman, 1986).

In this study, regression model is used as the common practice to identify the effects of health expenditure on MM. MMR is the dependent variable and government health expenditure is the independent variable.

$$
M M R_{i t}=\beta_{i}+\beta_{1} X_{i t}+Z_{i t}^{\prime} \gamma+\varepsilon_{i t}
$$

Where $M M R_{i t}$ is maternal mortality rate of country i in year t, Xit is public health expenditure for country i time t, and $Z_{i t}^{z}$ is set of control variables such as access to improved sanitation facilities (\% of population with access), real GDP per Capita, Women HIV Prevalence, household consumption, out of pocket health expenditure and external resource health expenditure $\beta_{1}$ coefficient of interest, and $\beta_{i}$ is country specific characteristics, $c_{i t}$ is the error term.

\section{Data Analysis and Interpretation}

Table 1: Results of Maternal Mortality-All 25 SSA Countries Sample

\begin{tabular}{|l|l|l|l|l|l|l|}
\hline \multicolumn{7}{|l|}{ IMPACT OF PUBLIC HEALTH EXPENDITURE ON MATERNAL MORTALITY } \\
\hline & $(1)$ & $(2)$ & $(3)$ & $(4)$ & $(5)$ & $(6)$ \\
\hline & OLS & OLS & RE & RE & FE & FE \\
\hline $\begin{array}{l}\text { Health expenditure, public (\% of } \\
\text { government expenditure) }\end{array}$ & $-0.40^{* * *}$ & $-0.23^{* * *}$ & $-0.30^{* * *}$ & $-0.17^{* * *}$ & $-0.30^{* * *}$ & $-0.16^{* * *}$ \\
\hline GDP per capita & $(0.05)$ & $(0.06)$ & $(0.03)$ & $(0.03)$ & $(0.03)$ & $(0.03)$ \\
\hline $\begin{array}{l}\text { Improved sanitation facilities (\% of } \\
\text { population with access) }\end{array}$ & & $-0.37 * * *$ & & $-0.56^{* * *}$ & & $-0.59^{* * *}$ \\
& & $(0.04)$ & & $(0.05)$ & & $(0.05)$ \\
\hline
\end{tabular}




\begin{tabular}{|c|c|c|c|c|c|c|c|}
\hline \multicolumn{2}{|c|}{$\begin{array}{l}\text { Women's share of population ages } \\
\text { 15+ living with HIV (\%) }\end{array}$} & & $\begin{array}{l}-0.13 \\
(0.21)\end{array}$ & & $\begin{array}{l}0.44 \\
(0.25)\end{array}$ & & $\begin{array}{l}0.68 * * \\
(0.26)\end{array}$ \\
\hline \multicolumn{2}{|c|}{$\begin{array}{l}\text { Household final consumption } \\
\text { expenditure }\end{array}$} & & $\begin{array}{l}0.10 \\
(0.09)\end{array}$ & & $\begin{array}{l}-0.16^{* *} \\
(0.05)\end{array}$ & & $\begin{array}{l}-0.16^{* *} \\
(0.05)\end{array}$ \\
\hline \multicolumn{2}{|c|}{$\begin{array}{l}\text { Out-of-pocket health expenditure } \\
\text { (\% of total expenditure on health) }\end{array}$} & & $\begin{array}{l}0.03 \\
(0.04)\end{array}$ & & $\begin{array}{l}-0.11 * * \\
(0.03)\end{array}$ & & $\begin{array}{l}-0.12 * * * \\
(0.03)\end{array}$ \\
\hline \multicolumn{2}{|c|}{$\begin{array}{l}\text { External resources for health (\% of } \\
\text { total expenditure on health) }\end{array}$} & & $\begin{array}{l}-0.05 \\
(0.03)\end{array}$ & & $\begin{array}{l}-0.06 * * * \\
(0.01)\end{array}$ & & $\begin{array}{l}-0.05 * * * \\
(0.01)\end{array}$ \\
\hline \multicolumn{2}{|l|}{$\mathbf{N}$} & 449 & 402 & 449 & 402 & 449 & 402 \\
\hline \multicolumn{2}{|l|}{ R-sq } & 0.150 & 0.542 & & & 0.173 & 0.638 \\
\hline \multicolumn{8}{|c|}{ Standard errors in parentheses } \\
\hline${ }^{*} \mathbf{p}<0.05$ & $* * \mathrm{p}<0.01$ & \multicolumn{3}{|c|}{$* * * \mathrm{p}<0.001 "$} & & & \\
\hline
\end{tabular}

\section{Source: Author's Results from STATA Software}

World Bank Indicators, 2017

\section{Table 2: Hausman specification test: FE vs RE}

The researcher have run both Fixed and Random Effects and the Hausman specification test rejects the hypothesis that difference in coefficients are not systematic hence FE estimation is more consistent.

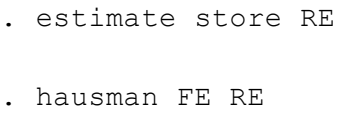

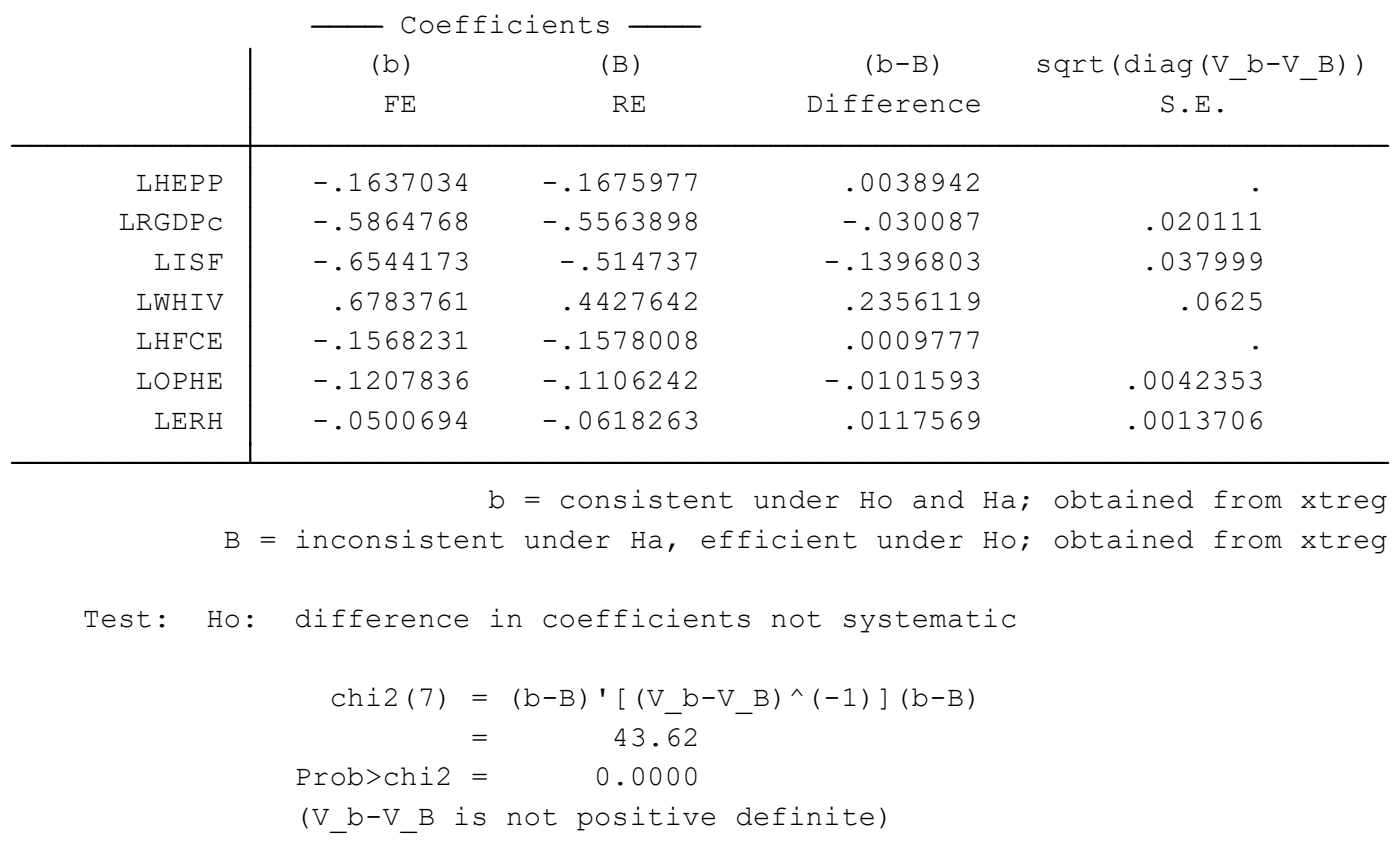


In general, the results are consistent with the empirical evidence documented in the literature. Government health expenditure is highly significant at $1 \%$ level in the pooled OLS, fixed effects and Random Effects estimations. Coefficient of this variable is +0.23 in the pooled OLS and +0.17 in the fixed effects estimation while its +0.16 random effects estimation. This imply that $1 \%$ increase in government health expenditure will reduce maternal mortality by $+0.23 \%,+0.17 \%$ and $+0.16 \%$ respectively. The interaction government health expenditure and GDP, good sanitation is significant as well. This means that the presence of real GDP per capita, out of pocket expenditure, prevalence of women living with HIV and household consumption have influence on the ratios or trends of maternal mortality in SSA countries.

Based on the Hausman specification tests, the fixed effects model was favored over the random effects model. The results presented in this section are thus based on the fixed effects model. Table 1 above presents results of maternal mortality as the dependent variable. Table 1 shows the results with each of the variable used in determining the effects of government health expenditure on maternal mortality. Guided by previous studies, the control variables included access to improved sanitation facilities, real GDP per capita, out of pocket expenditure, prevalence of women living with HIV and household consumption. However, other previous studies included female literacy rate, prevalence of female employed, access to improved sanitation facilities, real GDP per capita and out of pocket expenditure as their variables. Of these, access to improved sanitation facilities, real GDP per capita and out of pocket expenditure only were significant. Due to the mixed results from previous studies regarding the significance of the socioeconomic variables, there was no need for including female literacy rate and the prevalence of employed females. Therefore, with the exception of access to improved sanitation facilities, real GDP per capita and out of pocket expenditure the researcher did not include them.

The results of this study show that investing more on health care services is a crucial factor in health outcomes in SSA. It shows that public health care spending, significantly improves maternal health. As estimated, results indicate that investing in health, especially through public funds; helps enhance health facilities ultimately improving the whole health system implementation and performance. The results agree to the findings of other studies that investing and spending on health care affect the wellbeing of individual and growth of a country as a whole. For instance, (Servan-Mori, Avila-Burgos, Nigenda, \& Lozano, 2016) conducted a research and found sufficient positive association between health expenditure and health outcomes.

However, many SSA countries like Mozambique, Malawi, Nigeria and Zambia have poor health infrastructure and are less developed, and this leads to poor or little spending on health facilities. In this case, increased health spending is important as it plays a role in significantly making progress towards better health outcomes. While increasing health care spending, SSA countries need to utilize efficient and effective methods of allocating the resources and funds both in urban and rural areas to improve maternal health across the entire country. Allocation of resources and funds can include improving health infrastructure by building more health centers, investing in mobile clinics, increasing the number of beds in hospitals, personnel trainings, and availability of health equipment's and machines as well as medication and other preventive health care strategies and programs. Additionally, for SSA countries to improve the provision of maternal health, and reduce maternal deaths, it is crucial that governments spend above $10 \%$, in this case, health expenditure should range from 10 $18 \%$. Other studies have found out that countries like the United States invest most on health allocate between $10 \%$ to $20 \%$ of the total GDP, and mostly focus on medical personnel salaries, medical procedures as well as medication

Furthermore, the researcher emphasizes that the most important objective is to save mothers, women and the general citizens, through increased spending which is allocated equally. Thus states have to advocate for fair and equitable access to health amenities to enable the less privileged to have their health needs met. To do this, countries will need more resources to ensure that all individuals have access to good health services. In order to make this a success, high costs or extra health costs can be reduced by patients paying for certain services which is referred to as out-of-pocket contributions or spending. Studies conducted previously show that out-of-pocket spending reduces the desire for inessential health care attention which ultimately increases efficiency but fails to make any significant effects on maternal mortality reduction, (Zweifel and Manning 2000). Out of pocket spending is however driven by household incomes and consumption. A household with higher income is more likely to meet all its consumption and afford better health care access and medical bills from private health care centers, however it might be that households that fails to cover its consumption and have little income. Will not be able to afford any private health facilities thus rely on Government health facilities. Having said that good government health facilities put in place can rescue households that have lower incomes and households with higher incomes also would be in a position to access health facilities and invest some of their incomes in education or housing. 
With regard to the results and literature, HIV prevalence increases maternal mortality in SSA countries. In most cases, women living with HIV tends to be unproductive at workplaces and absent most of the times seeking health care also going for medical checkups. This leads to deductions in the actual salary depending on the days missed at work, ultimately deteriorating the health of the individual, affecting household consumption and the ability to maintain a healthy lifestyle necessary. Countries such as Botswana, South Africa and Lesotho prevalence rate is higher even though the countries' economy has been doing well. This raises questions on how much or how well the countries are investing in health to combat the wider spread of HIV and related diseases. In Botswana, most deaths happen as a result of HIV and related diseases. Thus it is important that countries such as Botswana, South Africa and Lesotho shift their focus on enhancing health care services, and investing more on health care as well as considering out of pocket expenditure on health and private assistance.

For SSA countries to combat maternal mortality there is need to focus and enhance good sanitation as well access to good sanitation services in all areas. Results of this study indicate that access to good sanitation also reduces maternal mortality and lack of sanitation services impacts negatively on the health of women. Meanwhile, addressing all the important aspects such as improved sanitation and increase spending on health might not be the only solution. This is because some countries in SSA have a good economy yet still have high maternal mortality or many challenges related to maternal health and some countries are clouded with corruption and political instabilities that might hinder success in the fight against maternal deaths. Countries such as Botswana and South Africa are deemed to be doing well economically amongst other countries yet the countries continue to lead in the prevalence of HIV. This indeed indicates that there are other factors that play a role in the prevalence of maternal deaths. On the other side, Malawi is one of the countries classified as low income, health facilities are inadequate yet the numbers of HIV cases are way below to the cases of Botswana, South Africa and Swaziland.

Above all, It is important to study the relationship between health care spending and health care outcomes with specific focus on maternal mortality in SSA between the period of 1997 to 2015 because SSA have had the most trends in poor health and disparities in health care access for the past year. In addition the region continues to remain poor, people live on less than a dollar a day thus making it hard survive, and to acquire good health care services nevertheless maintain a healthy lifestyle. Secondly life expectancy is stagnant in SSA countries with a life expectancy less than fifty years and in most cases this is due to poor health, HIV pandemic, poor living environment attributing to water borne diseases such as cholera, malaria, and poverty. Therefore it is important that Governments don't just increase funds in the health sector, it is also crucial to tackle other contributing factors that are not included in this study such as education, poverty, corruption and invent monitoring and evaluation tools that are specific for measuring the progress in the health sector with specific focus on maternal health care. For effectiveness and good progress, Government should also design a well detailed budget allocation plan that separates the allocation of funds on different programs and services such as preventive programs, educational activities on maternal health care, health infrastructures, health personnel, medication and equipment. This will help countries to identify arrears that need more funding and which areas are doing well with a certain amount. Taking into consideration the 2018 allocation of funds in Botswana, the Ministry of Health received the second largest share of $16.7 \%$ amounting to 17.54 billion pula. The amount will be used to purchase drugs, cover medical specialist fees, ARV therapy and government's contribution to Botswana Public Officers Medical Aid Schemes. Given this example, most countries fail to breakdown the budget accordingly indicating how percentages will be allocated to drugs or ARV Therapy and in what areas. This leads to funds being misused and some funds being used in more areas compared to others. Criticizing Botswana's allocation of funds, it fails to indicate how much will be spend on maternal health care services, such as PMTCT programs, preventive programs and as for ARV therapy, the sum is not broken down yet HIV is a major challenge that continues to lead to loss of lives among women.

\section{Policy Recommendations}

The findings suggest that public health spending, improved water source, sanitation facilities have caused significantly to the reduction in maternal mortalities achieved between years in SSA region. The findings have some implications for policymakers.

First there has been a greater demand for health services as well as more well-built health infrastructures, therefore there is need to pay more attention towards improving the quality of health care that citizens receive, in particular maternal care. SSA governments Mechanisms are crucial and would play an great role towards the betterment of quality and performance in the health sector and strengthen health systems and facilities to 
enhance delivery of maternal health care and the general health care.

Secondly, there is greater need that the Government increases their participation as well as the citizens when to come to budgeting issues related to health. Before formulating a budget or a program that aims to address a certain maternal health issue, Government officials should consult with the citizens and have an idea of what health crisis need major financing and how that health crisis affecting women can be best addressed. A platform to discuss budgets and include affected stakeholders and beneficiaries is important as it will aid and create an opportunity for efficient quantities to be budgeted for different areas.

Thirdly when allocating funds that will help address maternal health related issues in SSA, funds should be disbursed in areas such as health infrastructures, and every area in urban, rural and remote areas should at least have two health infrastructures. In areas where the population is high, there should be more health infrastructures that are within $5 \mathrm{~km}$ of the radius from households' compounds. Moreover, more investment should be made on mobile clinics in all areas.

Furthermore, more funds should also be invested in training personnel who will be fully equipped and trained in maternal health issues, to foster effectiveness's and efficiency in the provision of maternal health services, hospital centers should be fully equipped with equipment such as scans, medication, beds, and any other equipment needed. This will prevent a situation where patients have to move to other health centers to be assisted instead they will get the help they need at the health center in their area, this will also create an opportunity for effective monitoring of the patient's progress.

Fifthly, the results show that out of pocket health expenditure would also help reduce the maternal fatalities, however SSA is one of the regions that has high prevalent of poverty cases, therefore for individuals to pay for private health services would be a challenge especially for poor households. Thus, to improve and expand health services and quality in SSA, the government should have partnerships with private institutions that will help contribute to combating maternal mortality. Additionally, Private health centers can also play a role by providing services to women and the general population, and invoice the costs for each patient to the government, (Anyanwu \& Erhijakpor, 2007).

\subsection{Limitations of the Study}

This study has few limitations. First, some indicators/aspects of maternal mortality were not included by the researcher, such as physicians' density, birth attended by skilled health personnel and nutrition into the statistical models. This was because there was no available data recorded. Second, the dataset used is aggregate annual data at the national level and it would have been great to utilize household-level data to examine the disaggregated impact of health expenditures on different segments of the population. However, there is a chance to consider extending the study for future research in Southern Africa. In other countries such as India, studies have established that health expenditures have larger and lasting effects on the overall well-being of the poor (Gupta et al., 2003). This observation helps public policymakers to draft relevant policies that have bigger and effective impact on the population.

Despite the above concerns, the present study significantly enhances our understanding of the role of public expenditure on health in decreasing maternal mortality in developing countries today.

\subsection{Suggested Areas for Further Study}

For the purpose of future studies, it is recommended that considerable attempts should be made to disaggregate public health expenditure into the recurrent and capital mix. This is expected to help measure the different responsiveness of the explanatory variables on the disaggregated public healthcare expenditure. Additionally, it will be interesting to analyze the quality of governance effects on the effectiveness of public healthcare expenditure on maternal mortality. Other studies could narrow down the sample even further to one country to produce an even more specific result.

Furthermore, an understanding of the effectiveness of public health expenditures at the country's provincial or regional levels will be of paramount importance in SSA countries. Knowledge of the effectiveness of health expenditures at the regional levels will be very critical for governments to design and implement policies that influence the population and thus SSA and the observed pro-rich inequalities in health might be suggestive of problems with public health service delivery. In light of this point, further research might provide robust analysis at the country's provincial or regional level and inspect impact of public health expenditures at the individual level. 


\subsection{Conclusion}

The aim of the study was to analyze the effects of public health expenditure on maternal mortality in 25 SSA countries. The results presented show that public health care expenditure is significant and real GDP per capita; access to improved sanitation; household consumption and women's share of the HIV population are significantly associated with improved maternal health outcomes. Therefore the results of the study show that investing in health care is crucial towards improving maternal health status in SSA countries and it is of paramount that governments in SSA increase expenditures reserved to maternal health care service delivery.

\section{Acknowledgement}

I would like to express the deepest appreciation to my supervisor Professor Shin Jaeun and Professor Yun Heesuk of KDI School of Public Policy and Management, who both played a very great in guiding me throughout the research. Without their guidance and help this research, would not have been possible. I also place on record, my sense of gratitude to my family, colleagues and friends especially Mr. Belayneh Kassa Anagaw, Ms. Khalilah Hyde-Peyrefitte, Ms. Isabella Omariba, Ms. Polina Immel and Ms. Chaltu Daniel, for their support, guidance and unceasing encouragements which have provided the necessary intellectual premise for this achievement

\section{References}

Anyanwu, C., \& Erhijakpor, E. (2007). Health expenditures and health outcomes in Africa. African Development Bank Economic Research Working Paper No 91.

Anyanwu, J. C., \& Erhijakpor, A. E. (2007). Health Expenditures and Health Outcomes in. Tunisia: African Development Bank.

Bokhari, F., Gai, Y., \& Gottret, P. (2007). Government health expenditures and health outcomes. Health Economics 16, 257-273.

Burnside, C., \& Dollar, D. (1998). Aid, the Incentive Regime and Poverty Reduction. Washington DC: The World Bank.

Coghlan, B., Brennan, R., Ngoy, P., Dofara, D., Otto, B., \& Clements, M. (2006). Mortality in the Democratic Republic of Congo: A Nationwide Survey. Lancet: 367, 44-51.

Colbourn, T., Lewycka, S., Nambiar, B., Anwar, I., Phoya, A., \& Mhango, C. (2013). Maternal mortality in Malawi, 1977-2012. BMJ Open: Vol 3.

Commission on Macroeconomics and Health . (2001). Macroeconomics and Health: Investing in Health for Economic Development. Geneva: World Health Organisation.

Dennis J. Aigner, C. H. (984). Latent variable models in econometrics. Handbook of Econometrics Vol. 2, 13211393.

Devarajan, S. S. (1996). The Composition of Public Expenditure and Economic Growth. Journal of Monetary Economics, 37, 318-344.

Elola, J., Daponte, A., \& Navarro, V. (1995). Health indicators and the organization of health care systems in Western Europe. American Journal of Public Health, 85 No 10, 1397-1401.

Gao, Y., Zhou, H., Singh, N. S., Powell-Jackson, T., Nash, S., Yang, M., et al. (2017). Progress and challenges in maternal health in western China: a Countdown to 2015 national case study. Lancet Glob Health Vol $5,523-536$

Garret, L. (2007). The challenge of global health. Foreign Affairs, 86 (1), 14-38.

Gerdtham, U.-G., \& Ruhm, C. J. (2006). Deaths rise in good economic times: Evidence from the OECD. Economics and Human Biology $4,298-316$.

Grossman, M. (1972). The demand for health: A theoretical and empirical investigation. New York: Columbia University Press.

Hausman, Z. G. (1986). Errors in variables in panel data. Journal of Econometrics, Vol. 31, Issue 1, 93-118. 
Khan, K., Wojdyla, D., Say, L., Gülmezoglu, A., \& Look, P. V. (2006). WHO Analysis of Causes of Maternal Death: A Systematic Review. Lancet 367, 1066-1074.

Kim, T. K., \& Lane, S. R. (2013). Government Health Expenditure and Public Health Outcomes: A Comparative Study among 17 Countries and Implications for US Health Care Reform. American International Journal of Contemporary Research Vol. 3 No. 9, 8-13.

Kinney, M. V., Kerber, K. J., Black, R. E., Cohen, B., Nkrumah, F., Coovadia, H., et al. (2010). Sub-Saharan Africa's Mothers, Newborns, and Children: Where and Why Do They Die? PLOS Med Vol 7, No 6.

Lozano, R., Wang, H., Foreman, K., Rajaratnam, J., Naghavi, M., \& Marcus, J. (2011). Progress towards Millennium Development Goals 4 and 5 on maternal and child mortality: An updated systematic analysis. Lancet 378(9797), 1139-1165.

Makuta, I., \& O’Hare, B. (2015). Quality of governance, public spending on health and health status in Sub Saharan Africa: A panel data regression analysis. BMC Public Health vol 15, 932-943.

Manning, P. Z. (2000). Moral hazard and consumer incentives in health care. Handbook of Health Economics,, Vol. 1, 409-459.

Novignon, J., \& Olakojo, S. A. (2012). The Effects of Public and Private Health Care Expenditure and Health Status in Sub-Sahara Africa: New Evidence. Health Economics Review Vol 2 Number 22, 2-8.

Novignon, J., Olakojo, S. A., \& Nonvignon, J. (2012). The Effects of Public and Private Health Care Expenditure and Health Status in Sub-Sahara Africa: New Evidence. Health Economics Review Vol 2 Number 22, 2-8.

Poullier, J., Hernandez, P., Kawabata, K., \& Savedoff, D. (2002). Patterns of Global Health Expenditures: Results for 191 Countries. WHO Discussion Paper No 51.

Prata, N., Passano, P., Sreenivas, A., \& Gerdts, C. (2010). Maternal mortality in developing countries: Challenges in scaling-up priority interventions. Women's Health Vol 6, Number 2, 311-327.

Pritchett, D. F. (1999). The impact of public spending on health: Does money matter? Social Science \& Medicine, Vol. 49, Iissue 10, 1309-1323.

Rajkumar, A. S., \& Swaroop, V. (2008). Public spending and outcomes: Does governance matter? . Journal of Development Economics, 86 (1), 96-111.

Royston, E. (1989). Preventing maternal deaths. Geneva: World Health Organisation.

Sachs, J. D. (2004). Health in the Developing World: Achieving the Millennium Development Goals. Bulletin of the World Health Organization 82 (12), 947-949.

Sanjeev Gupta, M. V. (2002). The effectiveness of government spending on education and health care in developing and transition economies. European Journal of Political Economy Vol. 18, Issue 4, 717-737.

Servan-Mori, E., Avila-Burgos, L., Nigenda, G., \& Lozano, R. (2016). A Performance Analysis of Public Expenditure on Maternal Health in Mexico. PLOS ONE Vol 11 No 4, 1-14.

United Nations. (2013). World mortality report. New York: United Nations.

Wagner, A.H. (1883), Finanzwissenschaft. Leipzig: C. F. Winter

Wagstaff, A., \& Cleason, M. (2004). The Millennium Development Goals for Health: Rising to the Challenge. Washington DC: The World Bank.

Wirth ME, B. D. (2006). Setting the stage for equity-sensitive monitoring of the maternal and child health Millennium Development Goals. Bull World Health Organ 84(7), 519-27.

World Bank. (2000). World development indicators. Wahington, DC: The World Bank.

World Health Organisation. (2004). Health statistics and information systems. Geneva: World Health Organisation.

World Health Organisation. (2010). World health statistics. Geneva: World Health Organization.

World Health Organization. (2012). Trends in maternal mortality: 1990 to 2010. Geneva: WHO, UNICEF, UNFPA and The World Bank Estimates. 
World Health Organization: Regional Office for Africa. (2014). The Health of the People: What Works, The African Regional Health Report. Republic of Congo: WHO/AFRO Library Cataloguing.

Yaqub, J. O. (2012). Public Health Expenditure and Health Outcomes in Nigeria: The Impact of Governance. European Scientific Journal, 8(13), 189-201.

\section{APPENDICES}

\section{Appendix 1: List of Sub Saharan Africa Countries included in the study}

\begin{tabular}{|l|l|}
\hline 1. Angola & 14. Malawi \\
2. Botswana & 15. Mozambique \\
3. Burkina Faso & 16. Namibia \\
4. Burundi & 17. Nigeria \\
5. Cameroon & 18. Rwanda \\
6. Central African Republic & 19. Senegal \\
7. Cote d'Ivoire & 20. South Africa \\
8. Eritrea & 21. Sudan \\
9. Ethiopia & 22. Swaziland \\
10. Ghana & 23. Tanzania \\
11. Kenya & 24. Uganda \\
12. Lesotho & 25. Zambia \\
13. Liberia & \\
\hline
\end{tabular}

